University of Nebraska - Lincoln

DigitalCommons@University of Nebraska - Lincoln

$12-2003$

\title{
Bacteriolytic Activity of Selected Vertebrate Sera for Borrelia burgdorferi Sensu Stricto and Borrelia bissettii
}

Amy J. Ullmann

Division of Vector-Borne Infectious Diseases, National Center for Infectious Diseases, Centers for Disease Control and Prevention, Fort Collins, Colorado 80522

Robert S. Lane

Department of Environmental Science, Policy, and Management, Division of Insect Biology, University of California, Berkeley, California 94720

Klaus Kurtenbach

Department of Infectious Disease Epidemiology, Imperial College of Science Technology and Medicine, St. Mary's Campus, Norfolk Place, London

Michael Miller

Colorado Division of Wildlife, Fort Collins, Colorado

Martin E. Schriefer

Division of Vector-Borne Infectious Diseases, National Center for Infectious Diseases, Centers for Disease Control and Prevention, Fort Collins, Colorado 80522

Serfow thpsage fordaddlitionalaphthors:https://digitalcommons.unl.edu/publichealthresources

Part of the Public Health Commons

Ullmann, Amy J.; Lane, Robert S.; Kurtenbach, Klaus; Miller, Michael; Schriefer, Martin E.; Zeidner, Nordin; and Piesman, Joseph, "Bacteriolytic Activity of Selected Vertebrate Sera for Borrelia burgdorferi Sensu Stricto and Borrelia bissettii" (2003). Public Health Resources. 110.

https://digitalcommons.unl.edu/publichealthresources/110

This Article is brought to you for free and open access by the Public Health Resources at DigitalCommons@University of Nebraska - Lincoln. It has been accepted for inclusion in Public Health Resources by an authorized administrator of DigitalCommons@University of Nebraska - Lincoln. 


\section{Authors}

Amy J. Ullmann, Robert S. Lane, Klaus Kurtenbach, Michael Miller, Martin E. Schriefer, Nordin Zeidner, and Joseph Piesman 


\section{Bacteriolytic Activity of Selected Vertebrate Sera for Borrelia burgdorferi Sensu Stricto and Borrelia bissettii}

Amy J. Ullmann, Robert S. Lane ${ }^{\star}$, Klaus Kurtenbach†, Michael Millerł, Martin E. Schriefer, Nordin Zeidner, and Joseph Piesman, Division of Vector-Borne Infectious Diseases, National Center for Infectious Diseases, Centers for Disease Control and Prevention, Fort Collins, Colorado 80522; *Department of Environmental Science, Policy, and Management, Division of Insect Biology, University of California, Berkeley, California 94720; †Department of Infectious Disease Epidemiology, Imperial College of Science Technology and Medicine, St. Mary's Campus, Norfolk Place, London W21PG, U.K.; ‡Colorado Division of Wildlife, Fort Collins, Colorado 80526; To whom correspondence should be addressed.e-mail: aff1@cdc.gov

ABSTRACT: An in vitro assay to evaluate the bacteriolytic activity of the complement pathway was applied to 2 strains of Borrelia bissettii, CO501 and DN127, and compared with that of B. burgdorferi sensu stricto B31. Sera from mule deer (Odocoileus hemionus) and the Western Fence lizard (Sceloporus occidentalis) were completely borreliacidal for $B$. burgdorferi and for both strains of B. bissettii. Serum from Bobwhite quail (Colinus virginianus) was nonlytic for B. burgdorferi and partially lytic for $B$. bissettii strains, CO-501 and DN127. Serum from a New Zealand White rabbit (Oryctolagus cuniculus) was partially lytic for all 3 strains of Borrelia, whereas serum from white-footed mice (Peromyscus leucopus) were nonlytic for all 3 Borrelia strains. The spectrum of complement sensitivity of B. bissettii appears to be similar to that of European $B$. afzelii in that tested rodent serum is not lytic to these 2 genospecies. Interestingly, both $B$. bissettii and $B$. afzelii have been found to be closely associated with rodents. Complement sensitivity demonstrated in these experiments may suggest and possibly predict specific reservoir-host associations.

Bacteria within the Borrelia burgdorferi sensu lato group must survive and proliferate in the arthropod vector as well as the host. Part of this survival involves the complement cascade of the host immune system. It has been theorized that sensitivity to serum complement of vertebrates can help define potential reservoirs of Lyme borreliosis spirochetes (Kurtenbach et al., 2002). Previous work has demonstrated that Borrelia genospecies (specifically $B$. burgdorferi sensu stricto, $B$. afzelii, $B$. garinii, $B$. japonica, and $B$. valaisiana) vary in their sensitivities to different host-serum complement including deer, rodent, avian, and reptilian sera (Kurtenbach et al., 1998; Kuo et al., 2000; Nelson et al., 2000). Borrelia bissettii belongs to the B. burgdorferi sensu lato complex and has been found throughout North America and in Europe (Picken et al., 1996; Lane et al., 1998; Postic et al., 1998; Wright et al., 1998; R.N. Picken and M.M. Picken, 2000; Schneider et al., 2000; Lin et al., 2001). However, the host range of reservoir-competent and -incompetent animals for $B$. bissettii has not been fully determined (Maupin et al., 1994; Schneider et al., 2000). The purpose of this study was to test the borreliacidal activity of deer (Cervidae), quail (Phasianidae), mouse (Muridae), rabbit (Leporidae), and lizard (Iguanidae) sera against $B$. bissettii and, for comparative purposes, B. burgdorferi sensu stricto to determine which of these vertebrate groups may be potential reservoirs for this genospecies of spirochetes.

Borrelia burgdorferi sensu stricto B31 (Shelter Islands, New York), B. bissettii CO-501 (Larimer County, Colorado), and B. bissettii DN127 (Del Norte, California) were grown in complete BSK-H medium (Sigma Chemical Co., St. Louis, Missouri) (Sinsky and Piesman, 1989) at 33 C until a density of $10^{7}$ cells per ml was achieved (Piesman et al., 1990). For borreliacidal assays, $1 \mathrm{ml}$ of this culture was placed in BSK-H medium alone with no serum or antibiotics and incubated at $33 \mathrm{C}$ for $24 \mathrm{hr}$. Only low-passage isolates were used in these studies (passaged fewer than 10 times in vitro).

Sera were collected from 5 individual mule deer (Odocoileus hemionus) (collected from a captive deer herd at the College of Veterinary Medicine, Colorado State University), 5 individual Western Fence lizards (Sceloporus occidentalis) (collected from a salt marsh area adjacent to San Francisco Bay, where Ixodes pacificus are not found), 6 individual Bobwhite quail (Colinus virginianus) (collected from animals bred at Genesis Laboratories, Wellington Colorado), 7 individual white-foot- ed mice (Peromyscus leucopus) (obtained from the University of South Carolina Peromyscus Genetic Stock Center laboratory), and a single New Zealand White rabbit (Oryctolagus cuniculus). All sera, except for that of the Western Fence lizard, were obtained from captive animals previously unexposed to ticks and were pooled before use. Sera of $C$. virginianus, $P$. leucopus, O. cuniculus, and $O$. hemionus were all examined by ELISA and Western Blot assay and were found to be negative for antibodies to Borrelia spp., as previously described (data not shown) (Schwan et al., 1996). The Western Fence lizard sera were not tested for anti-Borrelia antibodies because sera taken from this area were previously tested and were found to be negative (Lane and Quistad, 1998). All sera were used without earlier freezing, except for sera from Western Fence lizards, which were shipped frozen and subsequently thawed once on ice before use.

Fifty microliters of $B$. burgdorferi cultures grown in serum-free BSK$\mathrm{H}$ was added to $50 \mu \mathrm{l}$ of test serum to give final volumes of $B$. burgdorferi serum suspensions of $100 \mu 1$ per well in 96-well microtiter plates (Nunc, Rochester, New York). All tests were run in triplicate with serum samples pooled from at least 5 individual animals, with the exception of New Zealand White rabbit serum as noted above. Some aliquots of sera were depleted of functional complement, or components thereof, by heat treatment $(0.5 \mathrm{hr}$ of incubation at $56 \mathrm{C})$, whereas other aliquots were left untreated. Controls consisted of Borrelia cultures diluted 1:1 in saline and incubated in serum-free media. The plates were sealed with sealing tape (Corning, Acton, Massachusetts) and incubated at 33 C (Kurtenbach et al., 1998). Each well was read at 0, 2, 4, and $22 \mathrm{hr}$ by collecting $10 \mu \mathrm{l}$ of culture suspension and then quantifying mobile spirochetes by dark-field microscopy ( $\times 400$ magnification). Immobilization and bacteriolysis were used as criteria for assessing borreliacidal activity.

All bacterial-serum wells were run in triplicate and the mean values of motile spirochetes calculated using the following equation: \% mortality $=([$ no. spirochetes in control - no. spirochetes in serum sample] $/$ [no. spirochetes in control]) $\times 100$, as described by Kuo et al. $(2000)$ Statistically significant differences in percentage of bacteriolysis were established using analysis of variance, with $P<0.05$ considered statistically significant.

Immobilization or lysis of spirochetes was apparent within $2 \mathrm{hr}$ of incubation and increased over time (Table I). Deer and lizard sera were completely borreliacidal for B. burgdorferi, B. bissettii CO-501, and B. bissettii DN127 $(P<0.01$, Table I). Serum collected from quail was nonlytic for $B$. burgdorferi $(P<0.001$, Table I) and partially lytic for both $B$. bissettii CO-501 and DN127 $(P<0.0414$, Table I). Rabbit serum was partially lytic for all 3 strains of Borrelia $(P=0.021)$, whereas mouse serum was nonlytic for all 3 Borrelia strains $(P<0.001$, Table I). Heat inactivation of sera $(0.5 \mathrm{hr}$ at $56 \mathrm{C})$ destroyed all borreliacidal effects (data not shown), suggesting that components of the complement system are involved in bacteriolysis.

Previous studies demonstrated that complement-related killing of $B$. burdorferi sensu lato generally acts through the alternate complement pathway and can be blocked by Factor H (Kraiczy et al., 2001; Stevenson et al., 2002). The spectrum of complement sensitivity of B. bissettii appears to be similar to that of European B. afzelii in that rodent serum is not lytic to these 2 genospecies (Kurtenbach et al., 1998). This differs from $B$. burgdorferi sensu stricto, which may thrive in both rodents and birds. Interestingly, both $B$. bissettii and B. afzelii have been found to 
TABLE I. Bacteriolytic activity of selected sera against Borrelia burgdorferi sensu stricto and Borrelia bissettii.

\begin{tabular}{lrccc}
\hline & & \multicolumn{3}{c}{$\%$ Bacteriolysis* } \\
\cline { 3 - 5 } Animal & & B. burgdorferi & B. bissettii & B. bissettii \\
species & Time (hr) & B31 & CO-501 & DN127 \\
\hline Mouse & 2 & 0 & 0 & 0 \\
& 4 & 0 & 0 & 4.23 \\
Rabbit & 22 & 2.67 & 0 & 7.19 \\
& 2 & $52.34 \dagger$ & $77.50 \dagger$ & $38.33 \dagger$ \\
Quail & 4 & $40.68 \dagger$ & $66.27 \dagger$ & $56.00 \dagger$ \\
& 22 & $40.32 \dagger$ & $69.35 \dagger$ & $56.25 \dagger$ \\
& 2 & $1.12 \ddagger$ & $20.00 \ddagger$ & $47.12 \ddagger$ \\
Lizard & 4 & $10.71 \ddagger$ & $63.83 \ddagger$ & $81.21 \ddagger$ \\
& 22 & $0.00 \ddagger$ & $72.22 \ddagger$ & $77.48 \ddagger$ \\
& 2 & $100.00 \S \|$ & $100.00 \S \|$ & $97.73 \S \|$ \\
Deer & 4 & $100.00 \S \|$ & $100.00 \S \|$ & $100.00 \S \|$ \\
& 22 & $100.00 \S \|$ & $100.00 \S \|$ & $100.00 \S \|$ \\
& 2 & $96.43 \S \|$ & $86.67 \S \#$ & $100.00 \S \|$ \\
& 4 & $96.27 \S \|$ & $100.00 \S \|$ & $100.00 \S \|$ \\
& 22 & $100.00 \S \|$ & $100.00 \S \|$ & $100.00 \S \|$ \\
\hline
\end{tabular}

* Bacteriolysis calculated using the equation: \% mortality $=([$ no. spirochetes in control - no. spirochetes in serum sample]/[no. spirochetes in control]) $\times 100$, as described in the Material and Methods section.

† Significantly different than mouse serum, $P=0.021$ (analysis of variance).

$\ddagger$ Significantly different than mouse serum, $P=0.0414$.

$\S$ Significantly different than mouse serum, $P<0.001$.

$\|$ Significantly different than quail serum, $P<0.001$.

\# Not significantly different than quail serum, $P=0.0605$.

be closely associated with rodents in North America (Postic et al., 1998; Schneider et al., 2000) and Europe (Humair et al., 1995). Previous studies have demonstrated that B. burgdorferi anticomplement protein found in tick saliva may determine vector competency for transmission (Valenzuela et al., 2000). However, the studies presented here were accomplished independent of tick transmission and suggest a prominent role for the direct ability of host blood components in determining specific reservoir species in nature.

\section{LITERATURE CITED}

Humair, P. F., O. Peter, R. Wallich, and L. Gern. 1995. Strain variation of Lyme disease spirochetes isolated from Ixodes ricinus ticks and rodents collected in two endemic areas in Switzerland. Journal of Medical Entomology 32: 433-438.

Kraiczy, P., C. Skerka, M. Kirschfink, V. Brade, and P. F. Zipfel. 2001. Immune evasion of Borrelia burgdorferi by acquisition of human complement regulators FHL-1/reconectin and Factor $\mathrm{H}$. European Journal of Immunology 31: 1674-1684.

Kuo, M. M., R. S. LANE, AND P. C. Giclas. 2000. A comparative study of mammalian and reptilian alternative pathway of complementmediated killing of the Lyme disease spirochete (Borrelia burgdorferi). Journal of Parasitology 86: 1223-1228.

Kurtenbach, K., S. De Michelis, S. Etti, S. M. Schafer, H. S. SewEll, V. Brade, AND P. Kraiczy. 2002. Host association of Borrelia burgdorferi sensu lato-the key role of host complement. Trends in Microbiology 10: 74-79.

, H. S. Sewell, N. H. Ogden, S. E. Randolph, and P. A. NutTALL. 1998. Serum complement sensitivity as a key factor in Lyme disease ecology. Infection and Immunity 66: 1248-1251.

LANE, R. S., AND G. B. QUISTAD. 1998. Borreliacidal factor in the blood of the western fence lizard (Sceloporus occidentalis). Journal of Parasitology 84: 29-34.

Lin, T., J. H. Oliver JR., L. GaO, T. M. Kollars JR., and K. L. Clark. 2001. Genetic heterogeneity of Borrelia burgdorferi sensu lato in the southern United States based on restriction fragment length polymorphism and sequence analysis. Journal of Clinical Microbiology 39: 2500-2507.

Maupin, G. O., K. L. Gage, J. Piesman, J. Montenieri, S. L. Sviat, L. VANDERZANDEN, C. M. HAPP, M. Dolan, AND B. J. Johnson. 1994. Discovery of an enzootic cycle of Borrelia burgdorferi in Neotoma mexicana and Ixodes spinipalpis from northern Colorado, an area where Lyme disease is nonendemic. Journal of Infectious Diseases 170: 636-643.

Nelson, D. R., S. Rooney, N. J. Miller, and T. N. Mather. 2000. Complement-mediated killing of Borrelia burgdorferi by nonimmune sera from sika deer. Journal of Parasitology 86: 1232-1238.

Picken, R. N., Y. Cheng, F. Strle, and M. M. Picken. 1996. Patient isolates of Borrelia burgdorferi sensu lato with genotypic and phenotypic similarities of strain 25015. Journal of Infectious Diseases 174: $1112-1115$.

, AND M. M. PICKEN. 2000. Molecular characterization of Borrelia spp. isolates from greater metropolitan Chicago reveals the presence of Borrelia bissettii. Preliminary report. Journal of Molecular Microbiology and Biotechnology 2: 505-507.

Piesman, J., J. R. Oliver, AND R. J. Sinsky. 1990. Growth kinetics of the Lyme disease spirochete (Borrelia burgdorferi) in vector ticks (Ixodes dammini). American Journal of Tropical Medicine and Hygiene 42: 352-357.

Postic, D., N. M. Ras, R. S. Lane, M. Hendson, and G. Baranton. 1998. Expanded diversity among Californian borrelia isolates and description of Borrelia bissettii sp. nov. (formerly Borrelia group DN127). Journal of Clinical Microbiology 36: 3497-3504.

Schneider, B. S., N. S. Zeidner, T. R. Burkot, G. O. Maupin, and J. PIESMAN. 2000. Borrelia isolates in Northern Colorado identified as Borrelia bissettii. Journal of Clinical Microbiology 38: 3103-3105.

Schwan, T. G., M. E. Schrumpf, B. J. Hinnebusch, D. E. Anderson JR., AND M. E. KonKel. 1996. GlpQ: An antigen for serological discrimination between relapsing fever and Lyme borreliosis. Journal of Clinical Microbiology 34: 2483-2492.

Sinsky, R. J., AND J. PIESMAN. 1989. Ear punch biopsy method for detection and isolation of Borrelia burgdorferi from rodents. Journal of Clinical Microbiology 27: 1723-1727.

Stevenson, B., N. El-Hage, M. A. Hines, J. C. Miller, and K. BabB. 2002. Differential binding of host complement inhibitor factor $\mathrm{H}$ by Borrelia burgdorferi Erp surface proteins: A possible mechanism underlying the expansive host range of Lyme disease spirochetes. Infection and Immunity 70: 491-497.

Valenzuela, J. G., R. Charlab, T. N. Mather, and J. M. Ribeiro. 2000. Purification, cloning, and expression of a novel salivary anticomplement protein from the tick, Ixodes scapularis. Journal of Biological Chemistry 275: 18717-18723.

Wright, S. A., R. S. LANE, AND J. R. Clover. 1998. Infestation of the southern alligator lizard (Squamata: Anguidae) by Ixodes pacificus (Acari: Ixodidae) and its susceptibility to Borrelia burgdorferi. Journal of Medical Entomology 35: 1044-1049. 